\title{
Differential Phagocytosis-Based Photothermal Ablation of Inflammatory Macrophages in Atherosclerotic Disease
}

\author{
Xin Wang, ${ }^{\perp, \#}$ Xiaoyu Wu, ${ }^{\perp, \#}$ Jinbao Qin, ${ }^{\perp, \#}$ Kaichuang Ye, ${ }^{\perp, \#}$ Feili Lai, ${ }^{\ddagger}$ Bo Li, ${ }^{*, \perp}$ Guanjie He, ${ }^{*}, \|$ \\ Xinwu Lu, ${ }^{*}, \perp$ Dan J. L. Brett, ${ }^{\dagger}$ and Ivan P. Parkin $*, \|$ \\ ${ }^{\perp}$ Department of Vascular Surgery, Shanghai Ninth People’s Hospital, Shanghai Jiao Tong University School of Medicine, Shanghai \\ 200011, China \\ "Christopher Ingold Laboratory, Department of Chemistry, University College London, London WC1E 7JE, U.K. \\ ${ }^{\dagger}$ Department of Chemical Engineering, University College London, London WC1H 0AJ, U.K. \\ ${ }^{\ddagger}$ State Key Laboratory of Molecular Engineering of Polymers, Department of Macromolecular Science, Fudan University, Shanghai \\ 200433, China
}

\begin{abstract}
Inflammatory macrophage $(\mathrm{M} \varphi)$-mediated atherosclerosis is a leading cause of mortality and morbidity worldwide. Photothermal therapy (PTT) has been demonstrated as an efficient strategy in killing target cells, and its application in the treatment of inflammation in atherosclerosis is developing. However, the choice of nanomaterials, mechanisms, and side effects are seldom considered. In this study, semiconductor nanomaterials, that is, $\mathrm{MoO}_{2}$ nanoclusters, were synthesized and used for the first time in PTT for inflammatory $\mathrm{M} \varphi$-mediated atherosclerosis. Based on cell differential phagocytosis, the optimum amount of $\mathrm{MoO}_{2}$ and treatment time were selected to exert the maximum ablation effect on $\mathrm{M} \varphi$ and minimal damage on endothelial cells without requiring additional target or selective groups. Moreover, $\mathrm{MoO}_{2}$-based PTT shows an excellent therapeutic effect on atherosclerosis by eliminating $\mathrm{M} \varphi$ in animal models, with no significant side effects observed. This study explores a new method of nanotechnology and pharmaceutical development by using and optimizing cost-effective metal oxide nanostructures in the treatment of atherosclerosis and motivates further research on minimizing the side effects of related materials.
\end{abstract}

KEYWORDS: molybdenum oxide, inflammation, macrophage, endothelial cell, photothermal therapy

\section{INTRODUCTION}

The treatment of macrophage $(\mathrm{M} \varphi)$-induced inflammationmediated atherosclerosis has recently gained great attention. ${ }^{1,2}$ The traditional method of stent implantation has been widely used in recanalizing atherosclerotic obliterative arteries., However, this interventional therapy fails to eliminate inflammatory $\mathrm{M} \varphi$, which increases the risk of in-stent restenosis. ${ }^{5,6}$ Therefore, the development of novel treatments is necessary and urgent.

Photothermal therapy (PTT) is a promising strategy in eliminating abnormally infiltrated or proliferating cells due to its noninvasive and selective therapeutic effect. The agents for PTT, such as nanostructured noble metals, organic materials, metal oxides, and chalcogenides, are promising candidates in eliminating cancer cells due to their fast photothermal response, excellent biocompatibility, and sometimes high sensitivity to photoacoustic or computed tomographic signals. $^{7-14}$ Several materials, such as gold nanorods and polypyrrole nanoparticles, have also been used in the experimental treatment of inflammation-related atherosclerotic disease in animal or human beings. ${ }^{15-17}$ Transition metal oxides, such as $\mathrm{MoO}_{3-x}$ and $\mathrm{WO}_{3-x}$, show dominant significance in PTT applications in killing target cells.
Compared to other agents, these materials exhibit a series of advantages, such as low cost and toxicity, easy fabrication, high photothermal conversion efficiency, and superb stability. ${ }^{8,10,14}$ However, the potential application of transition metal oxides for in vivo $\mathrm{M} \varphi$ elimination in atherosclerotic disease has not been considered and realized. Moreover, understanding the therapeutic mechanism of PTT agents in killing inflammatory $\mathrm{M} \varphi$ offers remarkable guidance for future improvements and design of these materials.

With the idea of using PTT to treat atherosclerotic diseases, concerns regarding the risk of serious complications must be raised since an overdose of nanomaterials may also cause normal cell death when eliminating target cells. Among normal cells in the vascular structure, endothelial cells (ECs) constitute a functional barrier inside the blood vessels and are essential in vascular physiological functions. ${ }^{18,19}$ Nevertheless, in previous studies, the optimal agent dose and laser time to avoid side effects of these materials have rarely been considered. 

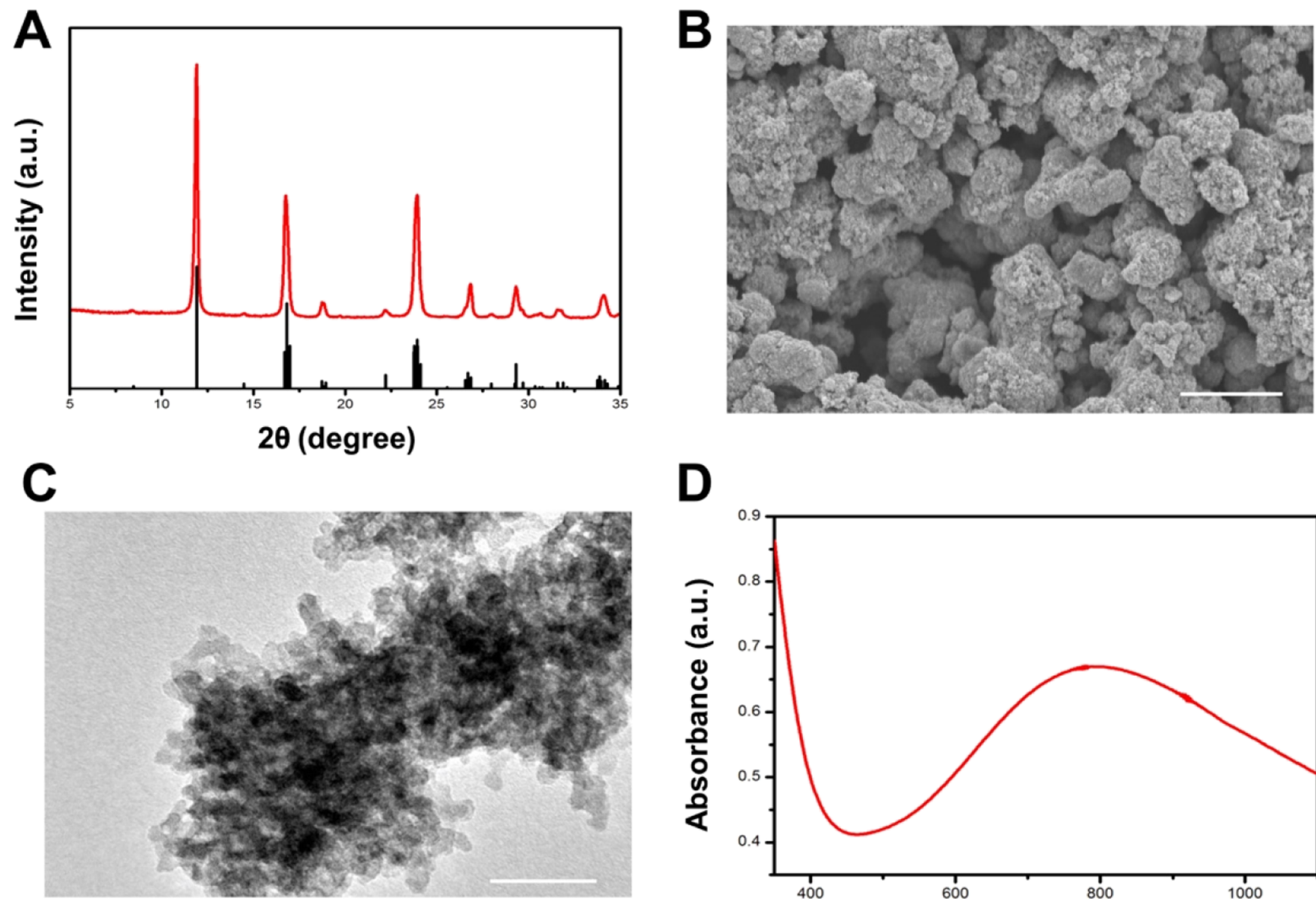

D

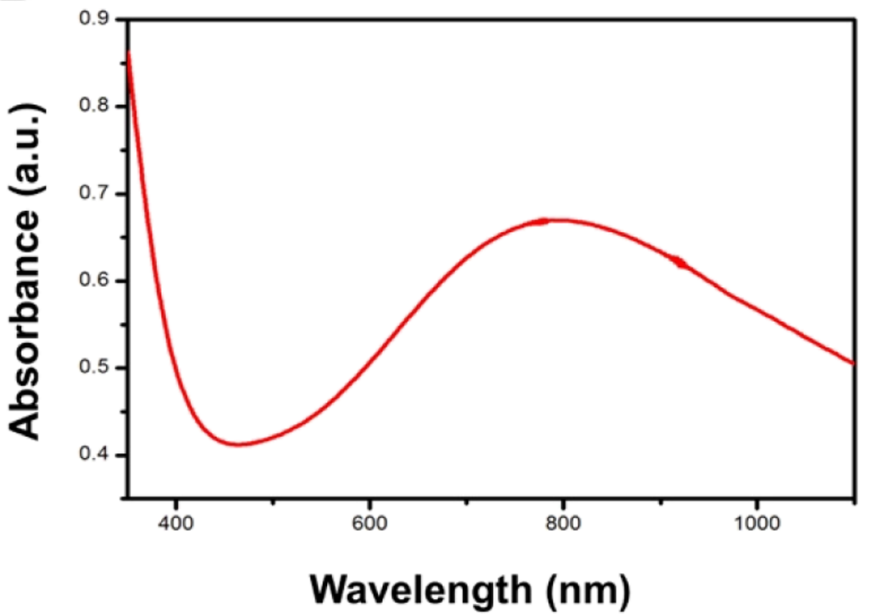

Figure 1. (A) XRD pattern and its corresponding standard $\mathrm{MoO}_{2}$ pattern. (B) SEM and (C) TEM images of the $\mathrm{MoO}_{2}$ nanoclusters, scale bars: 2 $\mu \mathrm{m}$ and $20 \mathrm{~nm}$, respectively. (D) UV-visible-NIR absorption spectrum of the $\mathrm{MoO}_{2}$ nanocluster solution at room temperature.

In this study, an effective and simple agent, that is, a $\mathrm{MoO}_{2}$ nanocluster, was synthesized and developed through a one-step hydrothermal process. The cytotoxicity and photothermal properties on $\mathrm{M} \varphi$ and ECs were determined in vitro. The optimal concentration of $\mathrm{MoO}_{2}$ nanoclusters and laser time were carefully explored and screened based on cell differential phagocytosis without using an additional target or selective groups. Furthermore, the histological analysis was examined to monitor the in vivo efficiency of PTT in eliminating inflammation in atherosclerotic animal models. More importantly, the therapeutic mechanism of the $\mathrm{MoO}_{2}$ nanoclusters was elucidated by cell apoptosis experiments.

\section{RESULTS AND DISCUSSION}

The materials were prepared via a facile one-step hydrothermal process using polyethylene glycol (PEG, confirmed by Fourier transform infrared spectroscopy (FTIR), Figure S1) as a surfactant and surface ligand to make the nanomaterials, $\mathrm{MoO}_{2}$ materials, hydrophilic.

Figure $1 \mathrm{~A}$ presents the tugarinovite structure, which is selfassembled into sea-urchin-like morphology (Figure 1B,C) with a broad light adsorption centered at $800 \mathrm{~nm}$ (Figure 1D). The end nanoclusters could remain stable when dispersed in water, phosphate buffer saline (PBS), and RPMI-1640 culture medium for a week (Figure S2A). The nanosheets retained their strong near infrared (NIR) absorption at room temperature for a week, indicating good dispersion in water, PBS, and RPMI-1640 culture medium (Figure S2B-D). The average size of as-prepared nanoclusters observed from TEM (Figure 1C) was around $40 \mathrm{~nm}$, while that of as-prepared nanoclusters in PBS solution measured by dynamic light scattering (DLS) was around $70 \mathrm{~nm}$ (Figure S3), indicating that those nanoclusters were mostly individually dispersed and had an appropriate size for use as a PTT agent. What is more, the size of nanoclusters in PBS determined by DLS shows very little change over time, also indicating a good dispersion. The temperature evolution of different concentrations of $\mathrm{MoO}_{2}$ nanoclusters under continuous laser irradiation of $808 \mathrm{~nm}$ was recorded, which shows a dramatic and smooth elevation in temperature with an increase in solution concentration (Figure 2A). In an aqueous solution containing $320 \mathrm{ppm} \mathrm{MoO}_{2}$ nanoclusters, the temperature changed from 20.8 to $57.2^{\circ} \mathrm{C}$ in $10 \mathrm{~min}$. The photothermal conversion efficiency of $\mathrm{MoO}_{2}$ nanoclusters was calculated to be $48.3 \%$ (Figure S4), which is comparable to those of other reported photothermal agents. $^{20,21}$ These in vitro results indicated that $\mathrm{MoO}_{2}$ nanoclusters are excellent PTT agents and have potential application in in vivo cell ablation. When PTT is used in the treatment of vascular inflammatory diseases, the purpose of selectively inhibiting the activity of inflammatory cells must be achieved. Simultaneously, damage to ECs, which constitute a functional barrier inside the normal blood vessels and are 

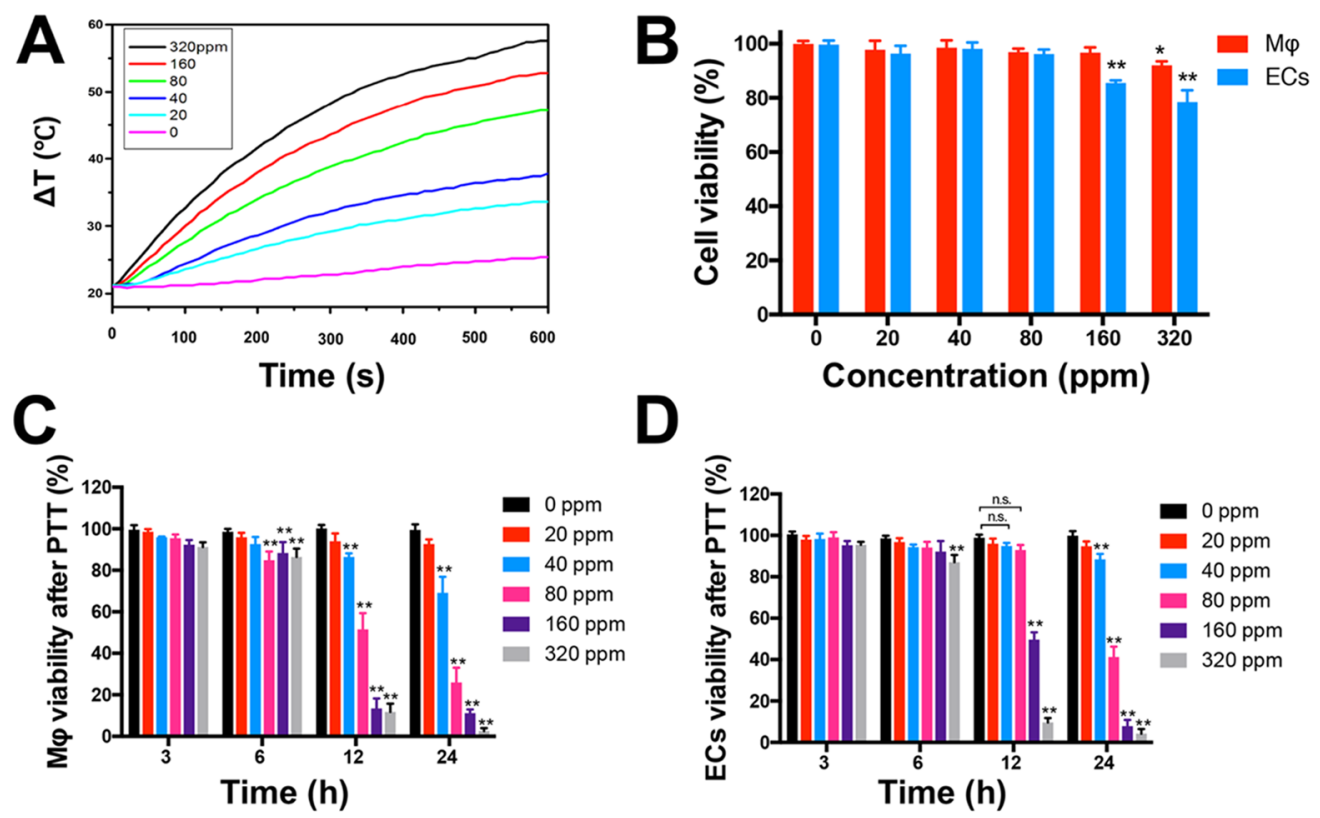

D
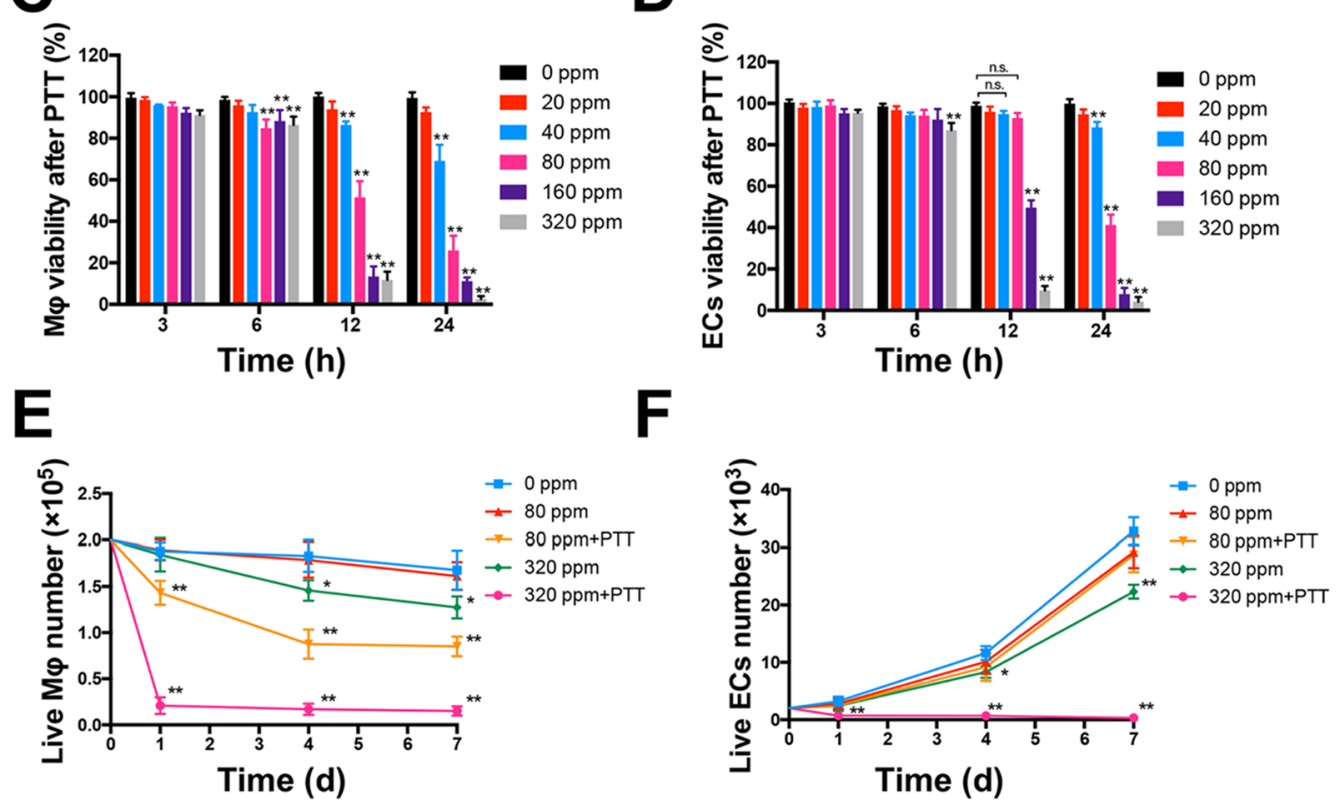

Figure 2. Screening of the optimal concentration and incubation time of $\mathrm{MoO}_{2}$ in photothermal therapy. (A) Photothermal effect of PBS and $\mathrm{MoO}_{2}$ nanoclusters in aqueous solution at different concentrations $(0,20,40,80,160$, and $320 \mathrm{ppm})$. (B) Relative cell viabilities of M $\varphi$ and ECs after incubation with $\mathrm{MoO}_{2}$ nanoclusters at different concentrations $(0,20,40,80,160$, and $320 \mathrm{ppm})$ for $24 \mathrm{~h}(n \geq 3, * P<0.05$, ** $P<0.01$ compared with $0 \mathrm{ppm}$ ). (C) Relative cell viabilities of $\mathrm{M} \varphi$ and (D) ECs after incubation with $\mathrm{MoO}_{2}$ nanoclusters at different concentrations (0, 20, $40,80,160$, and $320 \mathrm{ppm})$ for $3,6,12$, and $24 \mathrm{~h}$ under photothermal therapy $(n \geq 3, * P<0.05$, $* * P<0.01$ compared with 0 ppm). Cell proliferation experiments of (E) $\mathrm{M} \varphi$ and (F) ECs under different therapeutic conditions $(n \geq 3, * P<0.05$, ** $P<0.01$ compared with 0 ppm).

essential in vascular physiological functions, should be avoided. To achieve this purpose, primary mouse ECs and $\mathrm{M} \varphi$ were extracted, identified, and cultured as described previously. ${ }^{22,23}$ ECs grew with characteristic "cobblestone morphology" (Figure S5A), while $\mathrm{M} \varphi$ was round or oval with pseudopods (Figure S5B). To confirm that the isolated cells were ECs or $\mathrm{M} \varphi$, immunofluorescence staining was conducted using the von Willebrand factor (VWF) and F4/80 antibody, respectively. Figure S5C shows that ECs were stained with VWF. In contrast, Figure S5D shows that $\mathrm{M} \varphi$ clearly expressed F4/80 antibody. Flow cytometry further confirmed that the purity values of VWF-positive ECs and F4/80-positive $\mathrm{M} \varphi$ were as high as 94.9 and $90.2 \%$, respectively (Figure S5E,F). After identification, ECs and $\mathrm{M} \varphi$ were further used for subsequent experiments.

Figure $2 \mathrm{~B}$ shows that the cytotoxicity of $\mathrm{MoO}_{2}$ nanoclusters reflected by the relative viability of cells changes with the concentration of $\mathrm{MoO}_{2}$ nanoclusters. $\mathrm{MoO}_{2}$ nanoclusters with a concentration of $<80 \mathrm{ppm}$ showed no adverse effect on both cells, while significant cytotoxicity was observed when cells were exposed to $320 \mathrm{ppm}$ nanoclusters (ECs, $P<0.05$ compared with 0 ppm control; $\mathrm{M} \varphi, P<0.01$ compared with 0 ppm control). When exposed to $160 \mathrm{ppm} \mathrm{MoO}_{2}$ nanoclusters, $\mathrm{M} \varphi$ viability was not affected, while EC viability decreased accordingly $(P<0.01$ compared with 0 ppm control), indicating that ECs are more sensitive to high concentration of $\mathrm{MoO}_{2}$ nanoclusters than $\mathrm{M} \varphi$. The treatment time was further optimized by controlled experiments of cell viability and proliferation. Notably, with a concentration of $80 \mathrm{ppm}$ photothermal agents and a $12 \mathrm{~h}$ incubation followed with PTT, the EC viability was unaffected, while macrophage activity was significantly reduced (Figure 2C,D). Moreover, a cell proliferation experiment lasting for 7 days was performed after changing the culture solution to wash out un-phagocyted photothermal agents. As shown in Figure 2E,F, the viability of ECs was further shown not to be affected because the proliferation of treated ECs was the same as untreated normal ECs during this period. However, the viability of $\mathrm{M} \varphi$ sharply decreased after 4 days and showed no increase even after 7 days. These results indicate that PTT at the 12th hour after administration of $80 \mathrm{ppm} \mathrm{MoO}_{2}$ is the optimal therapeutic regimen. Under this condition, PTT only suppresses the viability of $\mathrm{M} \varphi$ and has no adverse effects on ECs. However, the possible treatment mechanism needs to be clarified.

Thermal effects can promote cell death through apoptosis or necrosis. In the clinic, removing target cells through inducing apoptosis rather than necrosis is more appealing and very favorable since apoptosis discourages an inflammatory 

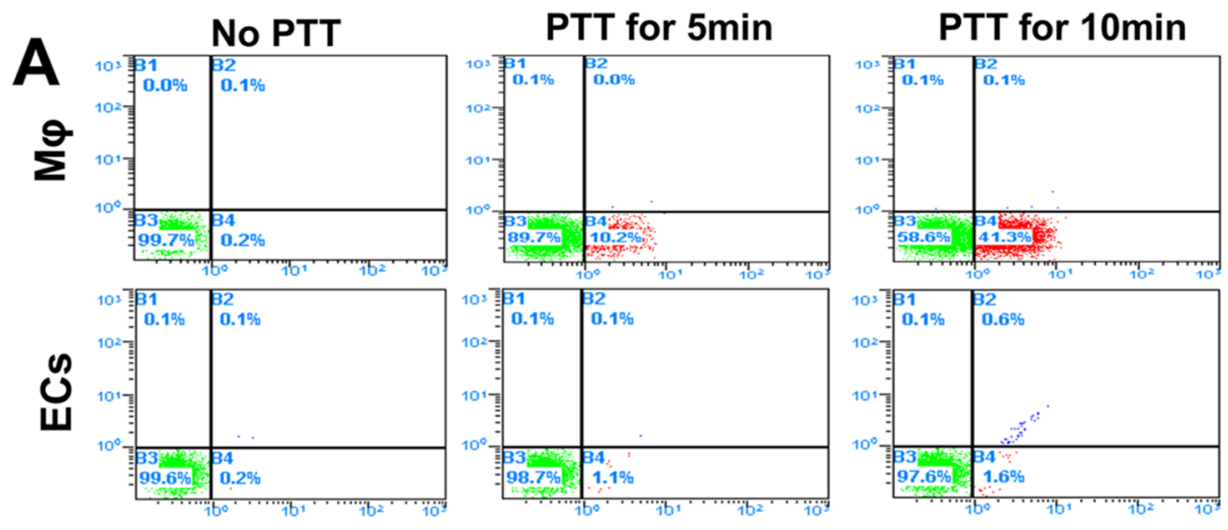

B
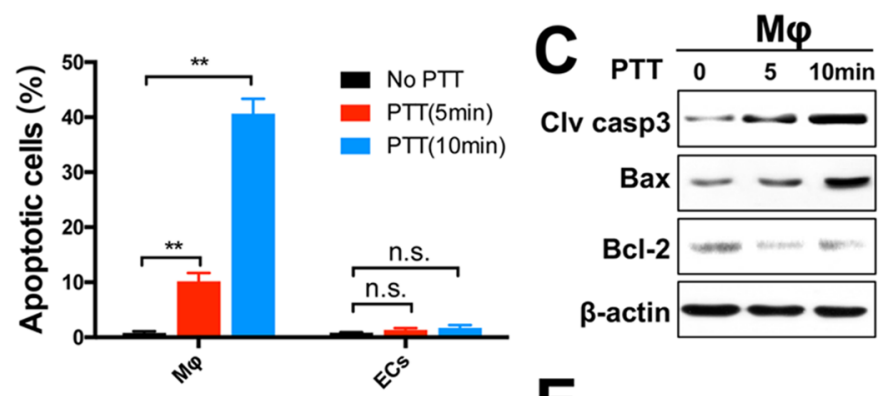

ECs
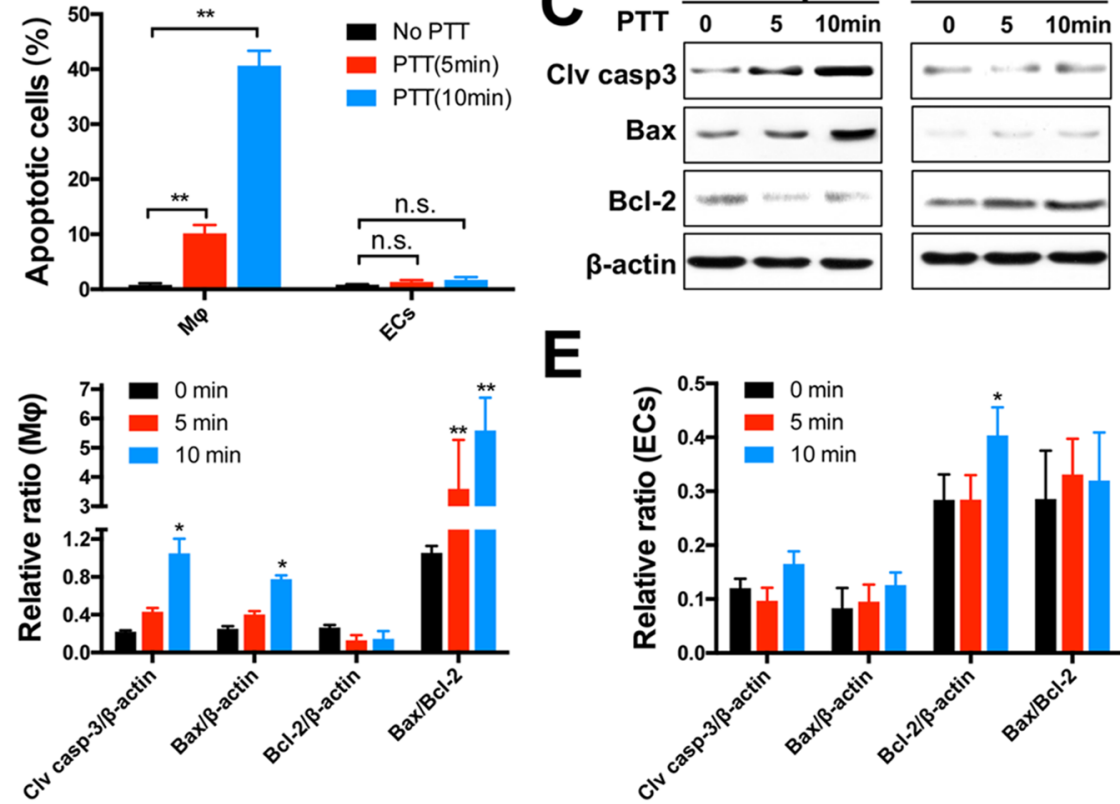

E

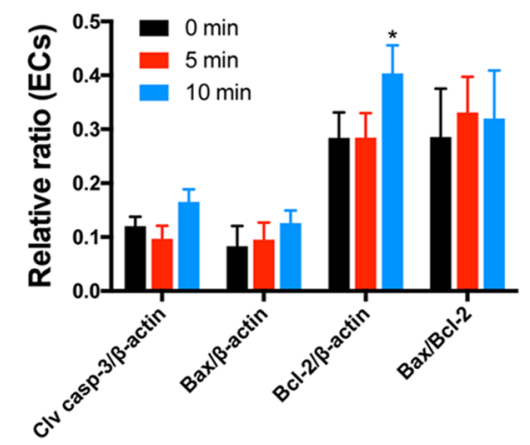

Figure 3. $\mathrm{MoO}_{2}$ nanocluster-based PTT induces $\mathrm{M} \varphi$ apoptosis under optimized conditions. (A) Flow cytometric analysis of cell apoptosis of $\mathrm{M} \varphi$ and ECs after incubation with $\mathrm{MoO}_{2}$ nanoclusters treated with or without PTT in different periods (5 or 10 min). (B) Quantification of apoptotic index of $\mathrm{M} \varphi$ and ECs treated by PTT with varying times $(n \geq 3$, **P<0.01 compared with no PTT). (C) Western blot analysis of apoptosisrelated proteins in $\mathrm{M} \varphi$ and ECs treated by PTT with varying times. The $\beta$-actin protein level was used as the control. (D,E) Quantification of apoptosis-related protein levels in $\mathrm{M} \varphi$ and ECs treated by PTT at varying times $(n \geq 3, * P<0.05, * * P<0.01$ compared with 0 min control).

response without hurting neighboring healthy cells. ${ }^{24}$ However, whether $\mathrm{MoO}_{2}$ nanocluster-based PTT induces cell death via apoptosis or necrosis is still unclear. To clarify this, the PTT-treated $\mathrm{M} \varphi$ and ECs were collected and incubated in annexin V/PI and assessed by flow cytometry. The percentages of $\mathrm{M} \varphi$ apoptosis after PTT for 0,5 , and $10 \mathrm{~min}$ were $0.83 \pm$ $0.25,10.18 \pm 1.50$, and $40.63 \pm 2.71 \%$, respectively, with a statistically significant difference between the PTT-treated and control groups $(P<0.01$, Figure 3A,B). In combination with the aforementioned cell proliferation assay, $\mathrm{MoO}_{2}$ nanoclusterbased PTT at given conditions can cause tremendous $\mathrm{M} \varphi$ apoptosis. The percentages of EC apoptosis after PTT for 0, 5, and $10 \mathrm{~min}$ were $0.87 \pm 0.06,1.33 \pm 0.35$, and $1.73 \pm 0.51 \%$, respectively, showing no significant difference between the PTT-treated and control groups $(P>0.05$, Figure 3A,B), although the proportion of EC apoptosis was slightly elevated. The previous cell proliferation assay in this study also demonstrated that $\mathrm{MoO}_{2}$ nanocluster-based PTT had no remarkable inhibitory effects on EC proliferation. Importantly, the percentage of apoptosis in $\mathrm{M} \varphi$ was significantly higher than that in ECs after either 5 or 10 min of PTT $(P<0.01$, Figure
3B). These results demonstrate that $\mathrm{MoO}_{2}$ nanocluster-based PTT at a specific concentration could promote $\mathrm{M} \varphi$ apoptosis while exerting rare side effects on ECs, thus exhibiting potential therapeutic effects for vascular inflammatory diseases.

Few studies have discussed the mechanism of $\mathrm{MoO}_{2}$ nanocluster-based PTT-induced apoptosis. Two major signaling pathways can trigger apoptosis: the mitochondrial (the intrinsic) pathway and the death receptor (the extrinsic) pathway. ${ }^{25}$ A previous study from Perez-Hernandez et al. reported that gold nanoprism-based PTT can activate the mitochondrial pathway of apoptosis and it is mediated by the nuclear-encoded proteins Bak and Bax and subsequent presence of caspase- 9 and caspase- 3 proteins. ${ }^{26}$ In our study, the expression of proteins associated with apoptosis was also investigated as shown in Figure 3C. Bax, a proapoptotic protein that belongs to the BCL-2 family, ${ }^{27}$ may also contribute to $\mathrm{MoO}_{2}$ nanocluster-based PTT. As shown in Figure 3C, PTT can promote the expression of $\operatorname{Bax}$ in $\mathrm{M} \varphi$, and it gradually increases with prolonged PTT time $(P<0.05$, Figure 3C,D). As for ECs, although the expression level of Bax was slightly elevated, there was no statistical difference $(P>$ 

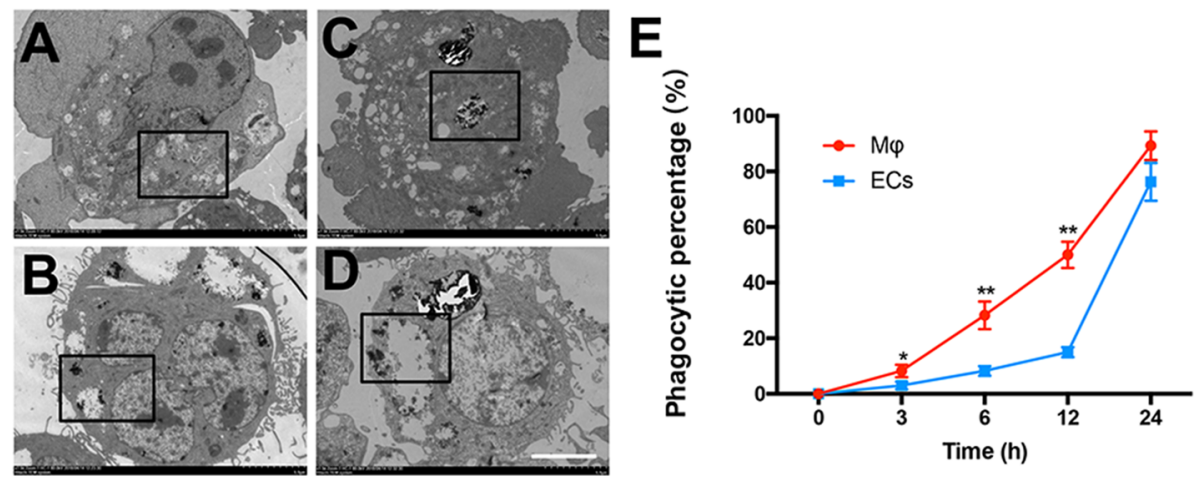

Figure 4. $\mathrm{M} \varphi$ showed stronger early phagocytic effect than ECs. Typical TEM images of (A) ECs and (B) $\mathrm{M} \varphi$ incubated with 80 ppm $\mathrm{MoO}{ }_{2}$ nanoclusters for $6 \mathrm{~h}$. (C) ECs and (D) $\mathrm{M} \varphi$ incubated with $80 \mathrm{ppm} \mathrm{MoO}$ nanoclusters for $24 \mathrm{~h}$. Scale bar: $5 \mu$ m. (E) Quantification of phagocytic levels of ECs and $\mathrm{M} \varphi$ incubated with $80 \mathrm{ppm} \mathrm{MoO}_{2}$ nanoclusters at varying times $(n \geq 3, * P<0.05$, ** $P<0.01$ compared with corresponding time points).

0.05 , Figure 3C,E). Bax is directly responsible for the loss of mitochondrial outer membrane integrity, which leads to cytochrome $\mathrm{C}$ release and caspase activation pathways to initiate apoptosis. ${ }^{27}$ As an important anti-apoptotic protein in the BCL-2 family, the expression of BCL-2 in $\mathrm{M} \varphi$ was not affected by PTT $(P>0.05$, Figure 3C,D). In contrast, BCL-2 in ECs showed a relatively escalating trend after $10 \mathrm{~min}$ of PTT $(P>0.05$, Figure 3C,E). Moreover, the Bax/BCL-2 ratio is an important parameter in evaluating the level of apoptosis. In this study, the proportion of $\mathrm{Bax} / \mathrm{BCL}-2$ in $\mathrm{M} \varphi$ was relatively higher after PTT $(P<0.05$, Figure $3 \mathrm{D})$, while no obvious statistically significant difference in ECs could be noted $(P>0.05$, Figure $3 \mathrm{E})$. The Bax/BCL-2 pathway culminates in the activation of caspase proteases and the cleavage of intracellular proteins. $\mathrm{MoO}_{2}$ nanocluster-based PTT was found to prominently enhance the expression of cleaved caspase 3 in $\mathrm{M} \varphi$, and its level gradually increases with treatment time. After 5 min of PTT, the expression of cleaved caspase 3 was nearly double compared to that of the control group, and after $10 \mathrm{~min}$ of treatment, the expression increased nearly 5 times $(P<0.05$, Figure 3C,D). However, in ECs, the expression level of cleaved caspase 3 was not distinctly upregulated at $5 \mathrm{~min}$ of PTT and slightly increased after 10 min of PTT without any statistically significant difference $(P>$ 0.05 , Figure $3 \mathrm{C}, \mathrm{E})$. Caspase 3 belongs to the caspase family and is one of the central regulators of apoptosis by cleaving targeted cellular proteins. ${ }^{28}$ The increased expression of cleaved caspase 3 indicates upregulation of apoptotic cell death. Thus, the mechanism of $\mathrm{MoO}_{2}$ nanocluster-based PTT is similar to that of gold nanoprism-mediated PTT reported by Perez-Hernandez et al. ${ }^{26}$ Moreover, the Live/Dead cell viability assay also demonstrated that $80 \mathrm{ppm} \mathrm{MoO}_{2}$ nanocluster-based PTT led to remarkable $\mathrm{M} \varphi$ death $(P<$ 0.01 , Figure $S 6)$, while EC viability was unaffected $(P>0.05$, Figure S6). Therefore, $\mathrm{MoO}_{2}$ nanocluster-based PTT may induce apoptosis of $\mathrm{M} \varphi$ through upregulation of proapoptotic protein, while ECs were not severely influenced in this process.

It is well known that $\mathrm{M} \varphi$ belongs to the mononuclear phagocytic system and has strong phagocytic ability. ${ }^{29,30}$ Therefore, it is easy to associate PTT properties with differential phagocytosis of $\mathrm{MoO}_{2}$ nanoclusters by $\mathrm{M} \varphi$ and ECs. Thus, a cell phagocytosis experiment was performed, and TEM was performed. Further, $80 \mathrm{ppm} \mathrm{MoO}_{2}$ nanoclusters were added in the medium of in vitro cultured ECs and $\mathrm{M} \varphi$ and coincubated for $3,6,12$, and $24 \mathrm{~h}$. Then, the cells were rinsed with PBS for at least three times to ensure that the unphagocyted $\mathrm{MoO}_{2}$ was washed out, and the cells were digested and collected for the phagocytic content of the cell to the $\mathrm{MoO}_{2}$ nanoclusters. As identified by the arrows in Figure 4 and Figure S7, $\mathrm{MoO}_{2}$ nanoclusters were mostly aggregated in lysosomes in both cell types. It is noted that the amount of phagocytic $\mathrm{MoO}_{2}$ nanoclusters in $\mathrm{M} \varphi$ was much higher than that in ECs at $3 \mathrm{~h}$ of incubation. The percentages of phagocytic $\mathrm{MoO}_{2}$ in $\mathrm{M} \varphi$ were $8.25 \pm 2.22 \%$, while it was only $3.0 \pm$ $1.41 \%$ in ECs at $3 \mathrm{~h}(P<0.05$, Figure $3 \mathrm{E})$. At $6 \mathrm{~h}$, the percentage was $28.25 \pm 4.92 \%$ in $\mathrm{M} \varphi$ (Figure $3 \mathrm{~B}$ and Figure $\mathrm{S} 7 \mathrm{~B}$ ) and $8.30 \pm 1.71 \%$ in ECs (Figure $4 \mathrm{~A}$ and Figure S7A), with obvious statistically significant difference $(P<0.01$, Figure 4E). At $12 \mathrm{~h}, \mathrm{M} \varphi$ phagocytized $50 \pm 4.69 \% \mathrm{MoO}_{2}$ nanoclusters, while ECs only phagocytized $15.0 \pm 1.82 \%(P$ $<0.01$, Figure 3E). More importantly, within 3-12 h, the average amount of $\mathrm{MoO}_{2}$ phagocytized by $\mathrm{M} \varphi$ was significantly higher than that of ECs $(P<0.05$, Figure S8). The percentage difference between the two phagocytic materials gradually decreased at $24 \mathrm{~h}$ because most $\mathrm{MoO}_{2}$ nanoclusters were phagocytized by both cells $(P>0.05$, Figure 4C,E, Figure S7C,D). This result indicated that $\mathrm{M} \varphi$ phagocytized a higher proportion of $\mathrm{MoO}_{2}$ nanoclusters than ECs within $12 \mathrm{~h}$, and it is clear that $\mathrm{M} \varphi$ can phagocytize $\mathrm{MoO}_{2}$ nanoclusters earlier and more rapidly. Since the given dose of $\mathrm{MoO}_{2}$ has not yet reached the average phagocytic threshold of both cells, almost all of the $\mathrm{MoO}_{2}$ is phagocytized over time, so the ratio of phagocytic $\mathrm{MoO}_{2}$ in $\mathrm{M} \varphi$ and ECs is similar at $24 \mathrm{~h}$. The phagocytic capacity of $\mathrm{M} \varphi$ is much higher than that of ECs, which has been recognized by Han et al. and van Furth et al. $^{29-31}$ Monocytes/M $\varphi$ are regarded as "professional" phagocytes, and their phagocytic ability depends on the immunoglobulin and complementary receptors at the cell surface, while ECs are considered as "nonprofessional" phagocytes with a low endocytic rate except when exposed to large amounts of nanoparticles.

To validate the feasibility of $\mathrm{MoO}_{2}$ nanocluster-based PTT in inhibiting vascular inflammation in vivo, a widely accepted model of arterial inflammation in $\mathrm{ApoE}^{-/-}$mice via placement of a silicone tube around the left common carotid artery was established, which can partially mimic the pathological changes of atherosclerosis. ${ }^{32}$ Inflammatory cell infiltration and proliferation gradually appeared in the vascular wall within the model, which caused obvious inflammation-related vascular wall hyperplasia and arterial stenosis. 

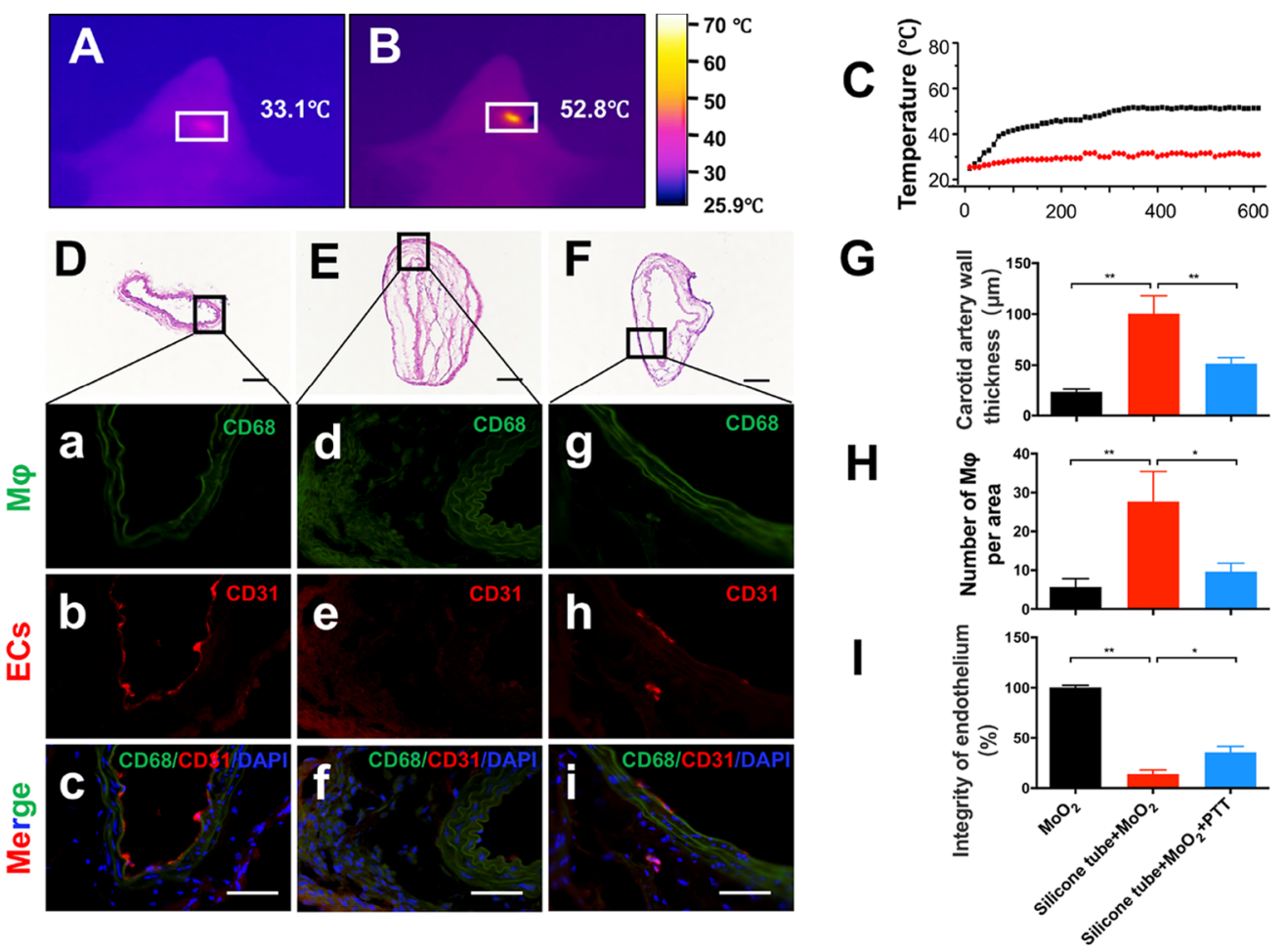

Figure 5. $\mathrm{MoO}_{2}$ nanocluster-based PTT attenuated vascular inflammation in vivo. Infrared thermal images of mice injected with $\mathrm{PBS}_{\text {(A) or }} \mathrm{MoO}_{2}$ nanoclusters (B) under laser irradiation. (C) Temperature change in regions as a function of the irradiation time (red, mice injected with PBS; black, mice injected with $\mathrm{MoO}_{2}$ nanoclusters). Representative $\mathrm{HE}$ images of the carotid artery in (D) the $\mathrm{MoO}_{2}$ group (control), (E) silicone tube $+\mathrm{MoO}_{2}$ group, and (F) silicone tube $+\mathrm{MoO}_{2}+$ PTT group. Scale bars: $50 \mu \mathrm{m}$. Representative immunofluorescence staining of $\mathrm{M} \varphi$ (a), ECs (b), and merge pictures (c) in the control group; $\mathrm{M} \varphi(\mathrm{d})$, ECs (e), and merge pictures (f) in the silicone tube $+\mathrm{MoO}_{2}$ group; and $\mathrm{M} \varphi$ (g), $\mathrm{ECs}(\mathrm{h}$ ), and merge pictures $(\mathrm{i})$ in the silicone tube $+\mathrm{MoO}_{2}+$ PTT group. Scale bars: $25 \mu \mathrm{m}$. (G) The vascular wall thickness of the carotid artery, $(\mathrm{H})$ number of the $\mathrm{M} \varphi$ per area, and $(\mathrm{I})$ integrity of the endothelium as a function of different situations $(n \geq 3, * P<0.05, * * P<0.01)$.

Due to inflammatory chemotaxis and strong phagocytosis, $\mathrm{M} \varphi$ that is enriched in carotid inflammation lesion can phagocytize the injected $\mathrm{MoO}_{2}$ nanoclusters. Based on this hypothesis, the effect of $\mathrm{MoO}_{2}$ nanocluster-based PTT on preventing the progression of carotid arterial inflammation was further studied (see the timeline diagram in Figure S9). To obtain a more efficient therapeutic effect, PTT on the 7th and 14th day was performed twice after the model was established. During the treatment, $80 \mathrm{ppm} \mathrm{MoO}_{2}$ solution was injected into the inflammatory area of the carotid artery under ultrasound guidance. PTT under an $808 \mathrm{~nm}$ laser (2 W/ $\mathrm{cm}^{2}$ ) at the carotid cannula was performed $12 \mathrm{~h}$ after $\mathrm{MoO}_{2}$ administration. During the laser treatment, infrared thermal images were captured using an infrared thermal camera (Figure $5 \mathrm{~A}, \mathrm{~B})$. A more obvious and rapid temperature increase to approximately $52.8{ }^{\circ} \mathrm{C}$ was observed in the left arterial area of $\mathrm{MoO}_{2}$-injected mice under laser irradiation (Figure 5B,C). This temperature is higher than that detected in vitro, probably due to local $\mathrm{MoO}_{2}$ accumulation in the inflammatory area caused by the injection. In mice injected with PBS (used as a control experiment for infrared thermal image), the surface temperature of the carotid artery inflammation regions increased slowly and remained $<33.1{ }^{\circ} \mathrm{C}$ in the entire irradiation process (Figures $4 \mathrm{C}$ and $5 \mathrm{~A}$ ). These results suggest that $\mathrm{MoO}_{2}$ nanoclusters have an excellent photothermal effect in vivo. To obtain a more effective treatment, $\mathrm{MoO}_{2}$-based PTT was performed for the second time at 14 days after modeling.

On the 28th day, the mice were sacrificed, and carotid arteries were carefully obtained, prepared, and evaluated by histological analysis. Compared with the carotid artery wall in the control group (Figure 5D), the inflammatory carotid wall had significantly thickened, and the lumen was relatively narrow (Figure 5E), as reflected by hematoxylin and eosin (HE) staining. PTT prevented carotid lumen stenosis, although no statistically significant difference was observed among the groups (Figure S10). PTT inhibited carotid wall hyperplasia caused by inflammation (Figure 5F) with evident statistically significant difference among the groups $(P<0.01$, Figure 5G), indicating that PTT could effectively inhibit arterial wall thickening, probably by alleviating inflammation.

Subsequently, the effectiveness of using $\mathrm{MoO}_{2}$ nanoclusterbased PTT in chronic arterial inflammation was further evaluated by immunofluorescence analysis. The endothelium was detected by staining with the CD31 antibody, while $\mathrm{M} \varphi$ was detected by staining with the CD68 antibody. Through immunofluorescence staining, it is found that the carotid endothelium in the sham group was intact (Figure 5b,c, red), there was little $\mathrm{M} \varphi$ infiltration in the wall (Figure 5a,c, green), while the inflammatory carotid wall was almost full of $\mathrm{M} \varphi$ infiltration $(P<0.01$, Figure $5 \mathrm{~d}$,f, green $)$. EC staining was quite weak $(P<0.01$, Figure 5e,f, red), which indicated that $\mathrm{M} \varphi$ could strongly mediate chronic vascular inflammation and may cause dysfunction of ECs. In mice treated with $\mathrm{MoO}_{2}$ nanocluster-based PTT twice, $\mathrm{M} \varphi$ infiltration was effectively alleviated (Figure 5g,i, green), and the endothelium was partially protected (Figure 5H,I, red). The distinct differences in $\mathrm{M} \varphi$ infiltration and endothelium integrity were observed between the control (Silicone $+\mathrm{MoO}_{2}$ ) and $\mathrm{MoO}_{2}$ nano- 
cluster-based PTT groups (Silicone $\left.+\mathrm{MoO}_{2}+\mathrm{PTT}\right)(P<$ 0.05 , Figure $5 \mathrm{H}, \mathrm{I})$.

To study the distribution and metabolism of the $\mathrm{MoO}_{2}$ nanoclusters, $\mathrm{ApoE}^{-/-}$mice were injected with $15 \mathrm{mg} \mathrm{kg}^{-1}$ $\mathrm{MoO}_{2}$ nanoclusters. These mice were sacrificed to extract major organs including heart, liver, spleen, lung, and kidney in different intervals of time (i.e., 1, 3, 7, 15 days, $n=4$ at each time point). These organs were then solubilized with nitric acid $(3 \mathrm{~mL})$ and heated to $120^{\circ} \mathrm{C}$. After the solution became clear, it was heated for another hour and then cooled down to room temperature. Each solution was diluted to $6 \mathrm{~mL}$ using deionized water for ICP-AES analysis to determine Mo content in each sample. It shows (Figure S11) that the $\mathrm{MoO}_{2}$ nanoclusters mainly accumulate in the liver and spleen, which indicates that this material was mainly degraded in these two organs. Furthermore, the major organs, including the heart, liver, spleen, lung, and kidney, were collected for histological analysis after the mice were sacrificed. No particle accumulation, obvious organ damage, or abnormal blood test results were noted due to local administration (Figure S12). The results suggested that the application of $\mathrm{MoO}_{2}$-based PTT in the prevention and treatment of vascular inflammatory lesions is safe and feasible.

It is clear that $\mathrm{M} \varphi$ plays important roles in inflammation, but it is worth noting that cells that infiltrated around the inflammatory area are not only $\mathrm{M} \varphi$ but also other cells such as neutrophils. ${ }^{33}$ The latter may also phagocytize $\mathrm{MoO}_{2}$ nanoclusters and may be further damaged by PTT. Simultaneously, some normal cells, such as ECs, may also phagocytize part of the $\mathrm{MoO}_{2}$ nanoclusters. The optimized conditions to avoid damage to these normal cells when performing PTT should be considered and screened. Although some of our previous studies have analyzed the efficacy of PTT in the elimination of $\mathrm{M} \varphi$ in inflammatory foci, further analysis of their effects on normal ECs has not yet been conducted. ${ }^{15,16}$

\section{CONCLUSIONS}

In conclusion, a facile material was utilized by means of a welldesigned approach to eliminate $\mathrm{M} \varphi$ without destroying ECs. The results indicate that $\mathrm{MoO}_{2}$ nanocluster-based PTT at specific concentrations could serve as an efficient treatment for inflammation in atherosclerosis. However, locally injected $\mathrm{MoO}_{2}$ may not be completely engulfed and may lead to local residues of $\mathrm{MoO}_{2}$ nanoclusters. Further studies could be focused on nanofabrication approaches to explore new photothermal materials or modify existing materials for actively targeting diseased tissues by improving the therapeutic effects and material utilization. The new finding could prevent local accumulation of materials and organ function damage caused by low targeting efficiency.

\section{METHODS}

Materials. Ammonium molybdate tetrahydrate $\left(\left(\mathrm{NH}_{4}\right)_{6} \mathrm{Mo}_{7} \mathrm{O}_{24}\right.$. $4 \mathrm{H}_{2} \mathrm{O}, 99.98 \%$ trace metals) and hydrochloric acid solution (32 wt \% in $\mathrm{H}_{2} \mathrm{O}, \mathrm{FCC}$ ) were purchased from Sigma-Aldrich (Sigma Chemical Co., St. Louis, MO, USA) and used without further purification. The RPMI-1640 medium, Dulbecco's modified Eagle medium (DMEM, formulated with low glucose, sodium pyruvate, L-glutamine, and HEPES), and penicillin-streptomycin antibiotic mixture were purchased from Gibco (Carlsbad, CA, USA). The EC growth supplement (ECGS) was purchased from Alfa Aesar (Thermo Fisher Scientific, U.K.). Primary antibodies, including anti-active caspase 3, anti-Bcl-2, anti-Bax, anti-VWF, anti-CD31, anti-F4/80, CD68, and anti-GAPDH, and secondary antibodies, including Alexa Fluor 488- and Alexa Fluor 647-conjugated antibodies, were obtained from Abcam (Cambridge, MA, USA). An HRP-conjugated secondary antibody and chemiluminescence kit were obtained from CST (Danvers, MA, USA). The FITC Annexin V Apoptosis Detection Kit I (BD Biosciences, CA, USA) was used to detect apoptosis by flow cytometry. The Cell Counting Kit-8 (CCK-8) was obtained from Dojindo (Kumamoto, Japan). The Live/Dead Cell Double Staining Kit was purchased from Sigma-Aldrich. Other chemicals were from Sinopharm Chemical Reagent Co., Ltd. (Shanghai, China) and used according to the manufacturer's instructions.

Synthesis and Characterization of $\mathrm{MoO}_{2} \cdot \mathrm{MoO}_{2}$ nanoclusters were synthesized by a one-step hydrothermal process as previously described. ${ }^{14}$ In a typical procedure, $0.1765 \mathrm{~g}$ of $\left(\mathrm{NH}_{4}\right)_{6} \mathrm{Mo}_{7} \mathrm{O}_{24}$ was first dissolved in $10 \mathrm{~mL}$ of $0.6 \mathrm{M}$ hydrochloric acid; then $25 \mathrm{~mL}$ of distilled water and $5 \mathrm{~mL}$ of PEG 400 were added and stirred for 30 min. Subsequently, the solution was moved to $50 \mathrm{~mL}$ Teflon-lined autoclaves and heated at $180{ }^{\circ} \mathrm{C}$ for $12 \mathrm{~h}$. The precipitate was finally collected by centrifugation, washed with ethanol, and deionized water three times. The powders were freeze-dried for further use.

The size and morphology of the $\mathrm{MoO}_{2}$ nanoclusters were characterized by transmission electron microscopy (TEM; JEM2100, Tokyo, Japan). UV-visible absorption spectra were measured with a Shimadzu UV-2550 UV-visible-NIR spectrophotometer (Shanghai, China) by using quartz cuvettes with an optical path of $1 \mathrm{~cm}$. X-ray diffraction (XRD) measurements were performed on a D/max-2550 PC X-ray diffractometer (XRD; Rigaku, Japan). FTIR spectra were measured by $\mathrm{KBr}$ pellet methods using an infrared spectrometer (Nicolet 6700, USA). The 808-nm semiconductor lasers were purchased from Shanghai Xilong Optoelectronics Technology Co. Ltd., China, whose power could be adjusted externally $(0-2 \mathrm{~W})$. The output power of lasers was independently calibrated using a handheld optical power meter (Newport model 1918-C, CA, USA).

Isolation and Identification of Aortic ECs. Mouse aortic ECs were isolated as previously described with some modifications. ${ }^{20}$ Briefly, after mice were euthanized, the aorta from the aortic arch to the abdominal aorta was isolated and rinsed with PBS containing $1000 \mathrm{U} / \mathrm{mL}$ heparin and then filled with $2 \%$ collagenase type II solution (Worthington Biochemical Corporation) in DMEM containing 10\% FBS and $1000 \mathrm{U} / \mathrm{mL}$ heparin. The isolated aorta was then closed with a microvascular clip at each end and maintained for incubation at $37^{\circ} \mathrm{C}$ for $45 \mathrm{~min}$. After incubation, ECs were flushed out using DMEM containing 10\% FBS and centrifuged at $1000 \mathrm{rpm}$ for $5 \mathrm{~min}$, and the precipitate was then resuspended and cultured in collagen I-coated dishes with the EC culture medium, which consisted of DMEM, $10 \%$ FBS, $10 \mathrm{mg} / \mathrm{mL}$ ECGS, and $1 \%$ penicillinstreptomycin.

For identification, ECs between passages 3 and 7 were cultured in a 6 well plate with a density of $1 \times 10^{6}$ cells per well. After $24 \mathrm{~h}$ of incubation, cells were fixed in $1000 \mu \mathrm{L}$ of $4 \%$ paraformaldehyde for 20 min, washed with PBS, and blocked with $5 \%$ bovine serum albumin. Consequently, cells were incubated with anti-VWF primary antibodies for $1 \mathrm{~h}$ at $37^{\circ} \mathrm{C}$ and then the Alexa-647-labeled secondary antibody for $1 \mathrm{~h}$ at room temperature. 4'6-Diamidino-2-phenylindole (DAPI) was used to stain nuclei for $2 \mathrm{~min}$ after $5 \%$ Triton $\mathrm{X}$ treatment. Subsequently, immunofluorescence images were acquired using a fluorescence microscope (Zeiss, NY). In the flow cytometry analysis, $1 \times 10^{6}$ ECs were collected and incubated with anti-VWF primary antibodies for $1 \mathrm{~h}$ at $37^{\circ} \mathrm{C}$ and then the Alexa-647-labeled secondary antibody for $45 \mathrm{~min}$ at room temperature. Isotype antibodies were used as the control. After washing in PBS, cells were analyzed using a flow cytometer (Beckman Coulter, Fullerton, CA).

Isolation and Identification of Bone-Marrow-Derived $\mathrm{M} \varphi$. Bone-marrow-derived $\mathrm{M} \varphi$ (BMDM) was isolated from the femur and tibia by flushing with the RPMI-1640 culture medium, which contains $10 \%$ FBS, $10 \mathrm{mM}$ HEPES, and 1\% penicillin-streptomycin, without the $\mathrm{M} \varphi$ colony stimulating factor (MCSF).$^{21}$ Cells were then pelleted and resuspended into the RPMI-1640 culture medium containing 10 $\mathrm{ng} / \mathrm{mL}$ MCSF. The fresh medium and growth factor were administered every 3 days of culture. On day 6, BMDM was applied for subsequent experiments. 
For identification, $\mathrm{M} \varphi$ was cultured in a 12 well plate with a density of $2 \times 10^{6}$ cells per well. After $24 \mathrm{~h}$ of incubation, cells were fixed in $500 \mu \mathrm{L}$ of $4 \%$ paraformaldehyde for $20 \mathrm{~min}$, washed with PBS, and blocked with $5 \%$ bovine serum albumin. Consequently, cells were incubated with anti-F4/80 primary antibodies for $1 \mathrm{~h}$ at $37^{\circ} \mathrm{C}$ and then the Alexa-488-labeled secondary antibody for $1 \mathrm{~h}$ at room temperature. DAPI was used to stain nuclei for 2 min after $5 \%$ Triton $\mathrm{X}$ treatment. Subsequently, immunofluorescence images were acquired using a fluorescence microscope (Zeiss, NY). For flow cytometry analysis, $2 \times 10^{6} \mathrm{M} \varphi$ were collected and incubated with Anti-F4/80 primary antibodies for $1 \mathrm{~h}$ at $37{ }^{\circ} \mathrm{C}$ and then the Alexa488-labeled secondary antibody for $45 \mathrm{~min}$ at room temperature. Isotype antibodies were used as the control. After washing in PBS, cells were analyzed using a flow cytometer (Beckman Coulter, Fullerton, CA).

Cytotoxicity. ECs and $\mathrm{M} \varphi$ seeded in 96 well plate with densities of $1 \times 10^{5}$ and $5 \times 10^{5}$ cells per well, respectively, were added with various doses of $\mathrm{MoO}_{2}(0,20,40,80,160$, and $320 \mathrm{ppm})$ for $24 \mathrm{~h}$. The cells were then washed three times with PBS after medium removal, and then $100 \mu \mathrm{L}$ of fresh medium and $10 \mu \mathrm{L}$ of CCK-8 reagent were added in each well and incubated at $37^{\circ} \mathrm{C}$ for $2 \mathrm{~h}$. After that, $100 \mu \mathrm{L}$ of incubated medium of each well was transferred to a new 96 well culture plate, and then the optical intensity at $450 \mathrm{~nm}$ was measured using a microplate reader (Thermo Labsystems, USA).

Screen for Optimal $\mathrm{MoO}_{2}$ Concentration and Incubation Time. To screen the optimal $\mathrm{MoO}_{2}$ concentration and incubation time that could induce $\mathrm{M} \varphi$ death without damage to ECs during PTT, ECs and $\mathrm{M} \varphi$ were incubated with various doses of $\mathrm{MoO}_{2}(0$, $20,40,80,160$, and $320 \mathrm{ppm})$ at various times $(3,6,12$, and $24 \mathrm{~h})$. After incubation, non-phagocyted $\mathrm{MoO}_{2}$ nanoclusters were washed out with PBS, and cells were treated by the $808 \mathrm{~nm}$ NIR laser irradiation with an output power density of $0.5 \mathrm{~W} \mathrm{~cm}^{-2}$ for $10 \mathrm{~min}$. Then, the treated cells were cultured for another $12 \mathrm{~h}$ and then analyzed using a CCK-8 kit.

Cell Viability and Proliferation. To assess cell viability and proliferation after PTT in vitro, ECs and $\mathrm{M} \varphi$ were seeded in 96 well plates at $5 \times 10^{3}$ and $1 \times 10^{4}$ cells per well, respectively, at $37^{\circ} \mathrm{C}$ in the presence of $5 \% \mathrm{CO}_{2}$ and incubated with $\mathrm{MoO}_{2}$ with optimized concentration and incubation time. After incubation, non-phagocyted $\mathrm{MoO}_{2}$ nanoclusters were washed out with PBS, and cells were treated by the $808 \mathrm{~nm}$ NIR laser irradiation with an output power density of $0.5 \mathrm{~W} \mathrm{~cm}{ }^{-2}$ for $10 \mathrm{~min}$. The treated cells were cultured for another 12 $\mathrm{h}$. Then a Live/Dead cell viability assay was performed according to the manufacturer's instructions and then observed to distinguish the live from dead cells through a fluorescence microscope. In another setup, ECs and $\mathrm{M} \varphi$ were seeded into 6 well plates at $5 \times 10^{3}$ and $1 \times$ $10^{4}$ cells per well, respectively. After PTT, they were further cultured at $37{ }^{\circ} \mathrm{C}$ in the presence of $5 \% \mathrm{CO}_{2}$, and cell numbers were counted at days 1,4 , and 7 to determine the effect of $\mathrm{MoO}_{2}$-based PTT on cell proliferation.

Apoptosis Analysis. Cell apoptosis after PTT in vitro was assessed by flow cytometry using the Annexin V/FITC Apoptosis Detection Kit I (BD Pharmingen). ECs and $\mathrm{M} \varphi$ were grown at $80-$ $90 \%$ confluency in 6 well plates and incubated with $\mathrm{MoO}_{2}$ with optimized concentration and incubation time. After incubation, nonphagocyted $\mathrm{MoO}_{2}$ nanoclusters were washed out with PBS, and cells were treated by $808 \mathrm{~nm}$ NIR laser irradiation with an output power density of $0.5 \mathrm{~W} \mathrm{~cm}{ }^{-2}$ for $10 \mathrm{~min}$. Then cells were harvested and resuspended in $100 \mu \mathrm{L}$ of binding buffer. Cells were double stained with $5 \mu \mathrm{L}$ of Annexin V-FITC and PI at room temperature for $15 \mathrm{~min}$ in the dark, and fluorescence was detected using a FACSCalibur flow cytometer (BD Biosciences, USA). At least 10000 cells were analyzed in each of the three independent experiments.

Western Blot Analysis. To analyze the expression of protein, ECs and $\mathrm{M} \varphi$ were grown at $80-90 \%$ confluency in 6 well plates and incubated with $\mathrm{MoO}_{2}$ with optimized concentration and incubation time. After incubation, non-phagocyted $\mathrm{MoO}_{2}$ nanoclusters were washed out with PBS, and cells were treated by $808 \mathrm{~nm}$ NIR laser irradiation with an output power density of $0.5 \mathrm{~W} \mathrm{~cm}^{-2}$ for 5 or 10 min. Then cells were lysed with ice-cold RIPA buffer, and proteins were separated by SDS-PAGE and transferred into the polyvinylidene fluoride membrane. Membranes were blocked for $2 \mathrm{~h}$ in Tris-buffered saline Tween-20 (TBST) supplemented with 5\% nonfat milk powder and then incubated overnight at $4{ }^{\circ} \mathrm{C}$ with primary antibodies (rabbit monoclonal anti-active-caspase 3, rabbit monoclonal anti-Bax, and rabbit polyclonal anti-Bcl-2) followed by $2 \mathrm{~h}$ of incubation with the HRP-conjugated secondary antibody. The chemiluminescence kit was used to detect signals, and then images were acquired using an LAS3000 machine (GE Healthcare Life Sciences). Protein bands were quantified by signal intensity with Image-Pro Plus 6.0 software, and relative intensities were calculated using the mean intensity of three or more independent experiments.

Cell Phagocytosis and Intracellular TEM. ECs $\left(1 \times 10^{6}\right.$ cells $)$ and $\mathrm{M} \varphi\left(1 \times 10^{6}\right.$ cells $)$ were incubated with $80 \mathrm{ppm} \mathrm{MoO}_{2}$ at various times $(3,6,12$, and $24 \mathrm{~h})$. After incubation at each time point, nonphagocyted $\mathrm{MoO}_{2}$ nanoclusters were washed out with PBS. Cells were then fixed by $2.5 \%$ glutaric dialdehyde solution and then collected for the TEM assay to determine their differential ability to phagocytose $\mathrm{MoO}_{2}$.

Animal Model and in Vivo PTT. Ethical approval of all animal experiments was granted by the Institution of Animal Care and Use Committee of Shanghai Ninth People's Hospital, Shanghai Jiao Tong University School of Medicine. ApoE ${ }^{-/-}$mice (8-12 weeks, male) were purchased from the Shanghai Research Center for Model Organisms (Shanghai, China) and housed under specific pathogenfree conditions with controlled temperature and humidity and $12 \mathrm{~h}$ light-dark cycles. Animals were acclimatized to the new environment for 1 week preoperatively. Carotid artery inflammation models were created as previously described. ${ }^{30}$ Therefore, the mice were anesthetized with an intraperitoneal injection of $40 \mathrm{mg} / \mathrm{kg}$ pentobarbital sodium. The left carotid artery was dissected and sheathed with a constrictive silica collar (length of $5 \mathrm{~mm}$, internal diameter of $0.2 \mathrm{~mm}$, and external diameter of $0.38 \mathrm{~mm}$ ). The contralateral right carotid artery was also isolated from the surrounding tissues to serve as an intra-animal control without a silica collar. After the models were created, the animals were fed a high fat diet.

In in vivo PTT, 18 mice that received model establishment were randomly assigned into two groups: silicone tube $+\mathrm{MoO}_{2}$ group and silicone tube $+\mathrm{MoO}_{2}+$ PTT group. Six ApoE ${ }^{-/-}$mice that did not receive model establishment were used as negative controls. On the 7 th day, $\mathrm{MoO}_{2}(80 \mathrm{ppm})$ was injected into the silicone tube under ultrasound guidance. After $12 \mathrm{~h}$ of injection, the mice in each group were perpendicularly subjected to $808 \mathrm{~nm}$ NIR laser irradiation in regions of carotid artery restenosis at a power density of $0.69 \mathrm{~W} \mathrm{~cm}$ for $10 \mathrm{~min}$. In the control group, $\mathrm{MoO}_{2}(80 \mathrm{ppm})$ was injected perivascularly, but laser irradiation was not applied. The real-time fullbody infrared thermal images under laser irradiation were obtained using a GX-300 photothermal medical device (Shanghai Infratest Electronics Co., Ltd., China) with an infrared camera. On the 14th day, all mice received another $\mathrm{MoO}_{2}$ injection followed by PTT.

Biodistribution. To study the biodistribution of $\mathrm{MoO}_{2}$, all treated mice were euthanized at each indicated time point. Then blood samples and specific organs, including the heart, liver, spleen, lung, kidney, and blood, were collected and incubated in nitric acid solution. $\mathrm{MoO}_{2}$ concentrations were quantified by inductively coupled plasma mass spectrometry (a Leeman Prodigy ICP-MS system, Hudson, NH03051, USA).

Histological and Immunofluorescence Analysis. After all treated mice were euthanized on day 28 , carotid arteries were harvested for histological and immunofluorescence analysis. The carotid arteries were fixed in $4 \%$ paraformaldehyde and embedded in paraffin for sectioning. Subsequently, for histological analysis, the carotid artery sections were deparaffinized with xylenes and graded ethanol and stained with HE for tissue morphology. The thickness of the vessel wall was calculated. The heart, liver, spleen, lung, and kidney were also collected for HE staining. For immunofluorescence staining, the carotid artery sections were deparaffinized, underwent antigen retrieval, and coincubated with antibodies against CD68 and CD31 overnight at $4{ }^{\circ} \mathrm{C}$ followed with corresponding secondary 
antibodies for $1 \mathrm{~h}$ at $37^{\circ} \mathrm{C}$. To confirm the specificity of the primary antibodies, non-immune IgG (R\&D Systems, AB105C, 6001A) was used as a negative control. At least three stained sections from each mouse were then examined with inverted fluorescence microscopy (Olympus IX81, Tokyo, Japan). $\mathrm{M} \varphi$ within the aortic walls was counted by determining the number of CD68-positive cells per aortic cross section. Endothelium integrity was expressed as the ratio of the length of the CD31-positive region to the lumen circumference.

Statistics. All quantitative data were expressed as mean \pm standard deviation. $t$ test was applied for comparison between the two groups using SPSS 18.0 software. For the comparison among multiple groups, one-way ANOVA was used followed with LSD tests. A $P$ value of $<0.05$ was considered statistically significant, and data were labeled with $(*)$ for $P<0.05$ and $(* *)$ for $P<0.01$.

\section{ASSOCIATED CONTENT}

FT-IR, UV-visible, DLS, photothermal effect, microscope images, Live/Dead cell results, enlarged TEM images of cells, quantification of $\mathrm{MoO}_{2}$ nanoclusters in a single cell, timeline diagram of in vivo study, in vivo vascular stenosis test, biodistribution of Mo by ICP-MS, HE images (PDF)

\section{AUTHOR INFORMATION}

\section{Corresponding Authors}

*E-mail: boli@shsmu.edu.cn (B.L.).

*E-mail: g.he@ucl.ac.uk (G.H.).

*E-mail: luxinwu@shsmu.edu.cn (X.L.).

*E-mail: i.p.parkin@ucl.ac.uk (I.P.P.).

\section{ORCID}

Bo Li: 0000-0001-7888-7519

\section{Author Contributions}

${ }^{\#}$ X.Wa., X.Wu., J.Q., and K.Y. have contributed equally to this work.

\section{Notes}

The authors declare no competing financial interest.

\section{ACKNOWLEDGMENTS}

This work was financially sponsored by the National Natural Science Foundation of China (Grant 81570432, 51890892, 81870346, 51702348, 81600205), Shanghai Sailing Program (17YF1421400), and Engineering and Physical Sciences Research Council (EP/L015862/1).

\section{REFERENCES}

(1) Otsuka, F.; Kramer, M. C. A.; Woudstra, P.; Yahagi, K.; Ladich, E.; Finn, A. V.; de Winter, R. J.; Kolodgie, F. D.; Wight, T. N.; Davis, H. R.; Joner, M.; Virmani, R. Natural Progression of Atherosclerosis from Pathologic Intimal Thickening to Late Fibroatheroma in Human Coronary Arteries: A Pathology Study. Atherosclerosis 2015, 241, $772-782$.

(2) Stojkovic, S.; Jurisic, M.; Kopp, C. W.; Koppensteiner, R.; Huber, K.; Wojta, J.; Gremmel, T. Circulating Micrornas Identify Patients at Increased Risk of In-stent Restenosis after Peripheral Angioplasty with Stent Implantation. Atherosclerosis 2018, 269, 197203.

(3) Almagor, M.; Keren, A.; Banai, S. Increased C-reactive Protein Level after Coronary Stent Implantation in Patients with Stable Coronary Artery Disease. Am. Heart. J. 2003, 145, 248-253.

(4) Hoffmann, R.; Mintz, G. S.; Mehran, R.; Kent, K. M.; Pichard, A. D.; Satler, L. F.; Leon, M. B. Tissue Proliferation Within and
Surrounding Palmaz-Schatz Stents is Dependent on the Aggressiveness of Stent Implantation Technique. Am. J. Cardiol. 1999, 83, 1170-1174.

(5) Kim, M. S.; Dean, L. S. In-stent Restenosis. Cardiovasc. Ther. 2011, 29, 190-198.

(6) Mitra, A. K.; Agrawal, D. K. In Stent Restenosis: Bane of the Stent Era. J Clin. Pathol. 2006, 59, 232-239.

(7) Cheng, L.; Yang, K.; Chen, Q.; Liu, Z. Organic Stealth Nanoparticles for Highly Effective in Vivo Near-Infrared Photothermal Therapy of Cancer. ACS Nano 2012, 6, 5605-5613.

(8) Chen, Z.; Wang, Q.; Wang, H.; Zhang, L.; Song, G.; Song, L.; Hu, J.; Wang, H.; Liu, J.; Zhu, M.; Zhao, D. Ultrathin PEGylated $\mathrm{W}_{18} \mathrm{O}_{49}$ Nanowires as a New $980 \mathrm{~nm}$-Laser-Driven Photothermal Agent for Efficient Ablation of Cancer Cells In Vivo. Adv. Mater. 2013, 25, 2095-2100.

(9) Dong, Q.; Wang, X.; Hu, X.; Xiao, L.; Zhang, L.; Song, L.; Xu, M.; Zou, Y.; Chen, L.; Chen, Z.; Tan, W. Simultaneous Application of Photothermal Therapy and an Anti-inflammatory Prodrug using Pyrene-Aspirin-Loaded Gold Nanorod Graphitic Nanocapsules. Angew. Chem., Int. Ed. 2018, 57, 177-181.

(10) Zhen, X.; Zhang, J.; Huang, J.; Xie, C.; Miao, Q.; Pu, K. Macrotheranostic Probe with Disease-Activated Near-Infrared Fluorescence, Photoacoustic, and Photothermal Signals for ImagingGuided Therapy. Angew. Chem., Int. Ed. 2018, 57, 7804-7808.

(11) Li, J.; Zhen, X.; Lyu, Y.; Jiang, Y.; Huang, J.; Pu, K. Cell Membrane Coated Semiconducting Polymer Nanoparticles for Enhanced Multimodal Cancer Phototheranostics. ACS Nano 2018, $12,8520-8530$.

(12) Zhen, X.; Xie, C.; Pu, K. Temperature-Correlated Afterglow of a Semiconducting Polymer Nanococktail for Imaging-Guided Photothermal Therapy. Angew. Chem., Int. Ed. 2018, 57, 3938-3942.

(13) Zhen, X.; Xie, C.; Jiang, Y.; Ai, X.; Xing, B.; Pu, K. Semiconducting Photothermal Nanoagonist for Remote-Controlled Specific Cancer Therapy. Nano Lett. 2018, 18, 1498-1505.

(14) Li, B.; Wang, X.; Wu, X.; He, G.; Xu, R.; Lu, X.; Wang, F. R.; Parkin, I. P. Phase and Morphological Control of $\mathrm{MoO}_{3-\mathrm{x}}$ Nanostructures for Efficient Cancer Theragnosis Therapy. Nanoscale 2017, 9, 11012-11016.

(15) Peng, Z.; Qin, J.; Li, B.; Ye, K.; Zhang, Y.; Yang, X.; Yuan, F.; Huang, L.; Hu, J.; Lu, X. An Effective Approach to Reduce Inflammation and Stenosis in Carotid Artery: Polypyrrole Nanoparticle-Based Photothermal Therapy. Nanoscale 2015, 7, 7682-7691.

(16) Qin, J.; Peng, Z.; Li, B.; Ye, K.; Zhang, Y.; Yuan, F.; Yang, X.; Huang, L.; Hu, J.; Lu, X. Gold Nanorods as a Theranostic Platform For in Vitro and in Vivo Imaging and Photothermal Therapy of Inflammatory Macrophages. Nanoscale 2015, 7, 13991-14001.

(17) Kharlamov, A. N.; Tyurnina, A. E.; Veselova, V. S.; Kovtun, O. P.; Shur, V. Y.; Gabinsky, J. L. Silica-Gold Nanoparticles for Atheroprotective Management of Plaques: Results of the NANOMFIM Trial. Nanoscale 2015, 7, 8003-8015.

(18) Peters, K.; Unger, R. E.; kirkpatrick, C. J.; Gatti, A. M.; Monari, E. Effects of Nano-Scaled Particles on Endothelial Cell Function in Vitro: Studies on Viability, Proliferation and Inflammation. J. Mater. Sci.: Mater. Med. 2004, 15, 321-325.

(19) Cines, D. B.; Pollak, E. S.; Buck, C. A.; Loscalzo, J.; Zimmerman, G. A.; McEver, R. P.; Pober, J. S.; Wick, T. M.; Konkle, B. A.; Schwartz, B. S.; Barnathan, E. S.; McCrae, K. R.; Hug, B. A.; Schmidt, A.-M.; Stern, D. M. Endothelial Cells in Physiology and in the Pathophysiology of Vascular Disorders. Blood 1998, 91, $3527-3561$

(20) Li, J.; Pu, K. Development of Organic Semiconducting Materials for Deep-Tissue Optical Imaging, Phototherapy and Photoactivation. Chem. Soc. Rev. 2019, 48, 38-71.

(21) Zhu, H.; Cheng, P.; Chen, P.; Pu, K. Recent Progress in the Development of Near-Infrared Organic Photothermal and Photodynamic Nanotherapeutics. Biomater. Sci. 2018, 6, 746-765.

(22) Kobayashi, M.; Inoue, K.; Warabi, E.; Minami, T.; Kodama, T. A Simple Method of Isolating Mouse Aortic Endothelial Cells. J. Atheroscler. Thromb. 2005, 12, 138-142. 
(23) Wu, C.; Xue, Y.; Wang, P.; Lin, L.; Liu, Q.; Li, N.; Xu, J.; Cao, $\mathrm{X}$. IFN $-\gamma$ Primes Macrophage Activation By Increasing Phosphatase and Tensin Homolog via Downregulation of miR-3473b. J. Immunol. 2014, 193, 3036-3044.

(24) Melamed, J. R.; Edelstein, R. S.; Day, E. S. Elucidating the Fundamental Mechanisms of Cell Death Triggered by Photothermal Therapy. ACS Nano 2015, 9, 6-11.

(25) Green, D. R.; Llambi, F. Cell Death Signaling. Cold Spring Harbor Perspect. Biol. 2015, 7, a006080.

(26) Pérez-Hernández, M.; del Pino, P.; Mitchell, S. G.; Moros, M.; Stepien, G.; Pelaz, B.; Parak, W. J.; Gálvez, E. M.; Pardo, J.; de la Fuente, J. M. Dissecting the Molecular Mechanism of Apoptosis during Photothermal Therapy Using Gold Nanoprisms. ACS Nano 2015, 9, 52-61.

(27) Wei, M. C.; Zong, W.-X.; Cheng, E.-H.; Lindsten, T.; Panoutsakopoulou, V.; Ross, A. J.; Roth, K. A.; MacGregor, G. R.; Thompson, C. B.; Korsmeyer, S. J. Proapoptotic BAX and BAK: A Requisite Gateway to Mitochondrial Dysfunction and Death. Science 2001, 292, 727-730.

(28) Dubey, M.; Nagarkoti, S.; Awasthi, D.; Singh, A. K.; Chandra, T.; Kumaravelu, J.; Barthwal, M. K.; Dikshit, M. Nitric OxideMediated Apoptosis of Neutrophils Through Caspase- 8 and Caspase3-dependent Mechanism. Cell Death. Dis. 2016, 7, No. e2348.

(29) Han, C. Z.; Juncadella, I. J.; Kinchen, J. M.; Buckley, M. W.; Klibanov, A. L.; Dryden, K.; Onengut-Gumuscu, S.; Erdbrügger, U.; Turner, S. D.; Shim, Y. M.; Tung, K. S.; Ravichandran, K. S. Macrophages Redirect Phagocytosis by Non-Professional Phagocytes and Influence Inflammation. Nature 2016, 539, 570-574.

(30) van Furth, R.; Raeburn, J. A.; van Zwet, T. L. Characteristics of Human Mononuclear Phagocytes. Blood 1979, 54, 485-500.

(31) van Furth, R. Current View on the Mononuclear Phagocyte System. Immunobiology 1982, 161, 178-185.

(32) von der Thüsen, J. H.; van Berkel, T. J. C.; Biessen, E. A. L. Induction of Rapid Atherogenesis by Perivascular Carotid Collar Placement in Apolipoprotein E-Deficient and Low-Density Lipoprotein Receptor-Deficient Mice. Circulation 2001, 103, 1164-1170. (33) Soehnlein, O.; Steffens, S.; Hidalgo, A.; Weber, C. Neutrophils as Protagonists and Targets in Chronic Inflammation. Nat. Rev. Immunol. 2017, 17, 248-261. 